\title{
Can Numerical Pain Rating Scale and Pain Catastrophic Scale Predict Lumbar Radiculopathy?
}

\author{
Osman Ersegun Batçık, (i) Bülent Özdemir
}

Department of Neurosurgery, Recep Tayyip Erdogan University Faculty of Medicine, Rize, Turkey

\begin{abstract}
Introduction: We wanted to investigate the relationship between the severity of pain and pain catastrophizing and Lasegue sign in patients with mechanical low back pain.

Methods: Three hundred and forty-five people with low back pain were divided into two groups as positive and negative according to the Lasegue sign. Numerical rating scale for pain (NRS-P) and pain catastrophizing scale (PCS) were administered to the participants and the predictive power of these tests for the Lasegue sign was investigated.

Results: The scores of both scales were found to be statistically significantly higher in the Lasegue positive group compared to the negative group. In the simple logistic regression analysis, it was determined that NRS-P and PCS could significantly predict Lasegue test positivity.

Discussion and Conclusion: It has been determined that NRS-P and PCS are tools that can be used for the presence of lumbar radiculopathy. The results of our study revealed that psychological factors such as catastrophizing are also important in the perception of pain, and it would be beneficial for clinicians to consider this situation while managing the treatment process.

Keywords: Lasegue sign; low back pain; pain catastrophizing; pain rating.
\end{abstract}

ow back pain is an important cause of pain, especially Lin developed and developing countries, and causes serious physical, psychological, and economic losses ${ }^{[1]}$. About $80 \%$ of people over the age of 40 experience low back pain at least once in their lives ${ }^{[2]}$. According to Turkish Statistical Institute 2016 data, it is seen that the incidence of low back pain, lumbar hernia, and other lumbar defects in the society is gradually increasing and its incidence has reached $27.1 \%^{[3]}$. Mechanical low back pain is induced by physical activity, relieved by resting, and mostly caused by a regional mechanical disorder. To define low back pain mechanically, causes such as inflammatory, infectious, tumoral, metabolic causes, fractures, and pain reflected from internal organs should be ruled out ${ }^{[4]}$.
Lasegue sign is one of the important clinical examination findings of lumbar radiculopathies, which are among the causes of mechanical low back pain. The Lasegue's sign is also known as the straight leg raising test. It is used in the differential diagnosis of sciatica. With the patient in the supine position, the affected limb is lifted up by holding the wrist until pain occurs. Pain occurring below 60 degrees is considered positive. A positive test consists of leg pain and paresthesia in the distribution of pain. It indicates nerve root compression ${ }^{[5]}$. Its sensitivity is about $91 \%$ and its specificity is $26 \%{ }^{[6]}$.

The numerical pain rating scale (NPRS) is a useful and easyto-use tool to assess the severity of low back pain ${ }^{[7,8]}$. The 
previous studies have shown that individuals' cognitive state also plays an important role in perceiving pain and assessing its severity. It has been shown in the literature that the tendency of patients to catastrophize events causes pain to be perceived as stronger than it actually is ${ }^{[9,10]}$. Catastrophizing was defined as "thinking about the worst possible outcome of incidents and threat and increasing the likelihood of experiencing this bad outcome." Based on this definition, the pain catastrophizing scale (PCS) was developed by Sullivan et al. ${ }^{[11]}$ to assess the severity of personal catastrophizing.

In our study, we aimed to investigate the relationship between pain intensity and catastrophizing pain, and the Lasegue sign, in patients with mechanical low back pain admitted to our outpatient clinic.

Thus, we will be able to determine whether the NPRS and PCS scores have a clinical value in recognizing the presence of lumbar radiculopathy.

\section{Materials and Methods}

\section{Participants}

This prospective study, after the approval of the Non-Invasive Clinical Research Ethics Committee of Recep Tayyip Erdoğan University (RTEU), dated December 23, 2020, and with the decision number 2020/247, was conducted with 345 patients of both sexes, who applied to RTEU Faculty of Medicine, Department of Brain and Nerve Surgery Outpatient Clinics with the complaint of mechanical back pain between December 2020 and February 2021.

Patients with a history of alcohol and substance abuse, who could not cooperate, who did not approve to participate in the study were excluded from the study.

Patients were informed about the study and those who accepted to participate in the study were directed to the inpatient service, and a neurosurgeon who had the necessary information about the study subject and scales recorded each patient's age, gender, body mass index, educational status, marital status, and existing comorbidities (hypertension, diabetes mellitus, ischemic heart disease, chronic obstructive pulmonary disease, depression, anxiety, etc.). NPRS was applied to assess pain intensity and PCS for pain catastrophizing. The study was conducted in accordance with the Declaration of Helsinki and approved by the institution's Ethics Committee (number and date). Written informed consent of the patients was obtained after the study protocol was fully disclosed.

Patients with positive Lasegue sign (LP) and those with negative Lasegue sign (LN) were defined in two different groups, and the groups were compared in terms of obtained data and calculated scale scores.

\section{NPRS}

Pain Intensity: The severity of low back pain was evaluated with the NPRS $(0=$ no pain and $10=$ maximum pain). The NPRS is a reliable method that evaluates subjective pain intensity, does not require literacy skills, is easy to use, and is accepted in the global literature ${ }^{[7]}$.

\section{PCS}

Severity of pain catastrophizing was evaluated with PCS, which was developed in 1995 by Sullivan et al..11] The Turkish version of the scale was evaluated by Süren et al. ${ }^{[12]}$ in terms of reliability and validity, and the Cronbach alpha coefficient was found to be 0.90 . The scale consists of 13 questions and has three subscales: Rumination, magnification, and helplessness. Each question is scored between 0 and 4 . The total score to be obtained from the scale varies between 0 to 52 . High scores indicate negative results. In many countries, its validity and reliability have been evaluated. ${ }^{[13]}$

\section{Statistical Analysis}

The statistical analysis of the data was performed with the SPSS for Windows 22 (SPSS, IBM, Chicago, IL, USA) package program. Frequencies, percentages, means, and standard deviations are given for sociodemographic variables. Chi-square test was used to compare categorical variables. Data on continuous variables were given as mean \pm standard deviation, and it was checked whether the Kolmogorov-Smirnov test conformed to the normal distribution. The significance of the difference between the groups was analyzed with the independent samples t-test, as it was determined to be distributed normally. Simple logistic regression analysis was used to evaluate whether the NPRS and PCS scores predicted the positivity of Lasegue test. Statistical significance was accepted as $p<0.05$ in all tests.

\section{Results}

Among the patients who applied to the Recep Tayyip Erdoğan University Medical Faculty Neurosurgery outpatient clinic with low back pain complaints, 345 patients (female $=172$ and male $=173$ ) who met the study criteria were included in the study and divided into two groups as LP and LN. There was no gender difference between LP and LN groups $\left(x^{2}=3.55 ; p=0.06\right)$. The mean age and standard deviation of 182 patients with LP was $47.96 \pm 11.16$, and the mean age and standard deviation of 163 patients with LN 
was $46.19 \pm 13.13$, with no significant difference in age between the two groups $(t=-1.35 ; p=0.17)$. There was no significant difference between the two groups according to their education levels $\left(x^{2}=6.38 ; p=0.09\right)$. When the groups were compared in terms of marital status, married ones were found to be in a statistically significant majority with 295 people $\left(x^{2}=6.58 ; p=0.01\right)$. The sociodemographic characteristics of the patients included in the study according to the groups are shown in Table 1.

The higher NPRS and PCS scores of LP patients were found to be statistically significant compared to $L N$ patients ( $t=-$ 8.72; $p \leq 0.001: t=5.54 ; p \leq 0.001$, respectively) (Table 2 ).

The results of the simple logistic regression analysis showed that NPRS scores significantly predicted whether the Lasegue test was positive in the participants $\left(x^{2}(1)=67.6\right.$; $p<0.001$, Nagelkerke $R 2=0.24)$. According to the HosmerLemeshow test, this model was found to be suitable for the data $\left(x^{2}(5)=8.21, p=0.145\right)$. Overall, the model correctly classified $67.2 \%$ of the participants, resulting in an increase of $14.4 \%$ compared to the model where only the constant was taken (52.8\%). The results showed that 1 point increase in NPRS resulted in a 0.56 increase in log odds of LP test (\%95 Cl =\%1.51-2.04) (Table 3).

In the simple logistic regression analysis, where PCS scores were taken as independent variables, it was shown that PCS scores significantly predicted whether the Lasegue test was positive in the participants $x^{2}(1)=29.33$; $\mathrm{p}<0.001$, Nagelkerke $\mathrm{R} 2=0.11)$. According to the Hosmer-Lemeshow test, it was determined that this model fits the data well $\left(x^{2}(8)=9,56, p=0.29\right)$. Overall, the model correctly classified $60.6 \%$ of the participants, resulting in a $7.8 \%$ increase over the model where only the constant was taken $(52.8 \%)$. The results showed that a 1 point increase in PCS resulted in an increase of 0.05 in the log odds of LP test (\%95 Cl=\% 1.03-1.07) (Table 3).

\section{Discussion}

Limited straight leg raising (Lasegue sign) from sciatica stretch tests is an important part of the physical examination in patients presenting with the complaint of low back pain. However, it is also claimed that the method of performing this test, which has been used as an important clinical sign in medicine for 150 years, varies according to the physician ${ }^{[14]}$. In a prospective study in which the correlation between the results of the Lasegue sign and the surgical finding was investigated in a sample of 55 patients, the Lasegue sign was found to be positive in 49 patients $(89 \%)^{[15]}$. In the study conducted by Görgülü et al. ${ }^{[16]}$, the
Table 1. Comparison of the two groups in terms of sociodemographic characteristics

\begin{tabular}{|c|c|c|c|c|c|c|c|}
\hline & \multicolumn{2}{|c|}{$\begin{array}{l}\text { Lasegue } \\
\text { positive } \\
(n=182)\end{array}$} & \multicolumn{2}{|c|}{$\begin{array}{c}\text { Lasegue } \\
\text { negative } \\
(n=163)\end{array}$} & \multirow[t]{2}{*}{$x^{2}$} & \multirow[t]{2}{*}{ df } & \multirow[t]{2}{*}{$\mathbf{p}$} \\
\hline & $\mathbf{n}$ & $\%$ & $\mathbf{n}$ & $\%$ & & & \\
\hline \multicolumn{8}{|l|}{ Gender } \\
\hline Female & 82 & 47.7 & 90 & 52.3 & 3.55 & 1 & 0.06 \\
\hline Male & 100 & 57.8 & 73 & 42.2 & 6.58 & 1 & $0.01^{*}$ \\
\hline \multicolumn{8}{|c|}{ Marital status } \\
\hline Single & 18 & 36.0 & 32 & 64.0 & & & \\
\hline \multirow[t]{2}{*}{ Married } & 164 & 55.6 & 131 & 44.4 & & & \\
\hline & Mean & SD & Mean & SD & $a_{\mathbf{t}}$ & & \\
\hline Age & 47.96 & 11.16 & 46.19 & 13.13 & -1.35 & & 0.17 \\
\hline
\end{tabular}

Chi-square test; ${ }^{\mathrm{a}}$ : Independent samples t-test; SD: Standard deviation; $\mathrm{p}<0.05^{*}$.

Table 2. Comparison of the two groups in terms of scale scores

\begin{tabular}{|c|c|c|c|c|c|c|}
\hline & \multicolumn{2}{|c|}{$\begin{array}{l}\text { Lasegue } \\
\text { positive } \\
(n=182)\end{array}$} & \multicolumn{2}{|c|}{$\begin{array}{c}\text { Lasegue } \\
\text { negative } \\
(n=163)\end{array}$} & \multirow[t]{2}{*}{$t$} & \multirow[t]{2}{*}{$\mathbf{p}$} \\
\hline & Mean & SD & Mean & SD & & \\
\hline NPRS & 6.85 & 1.69 & 5.33 & 1.52 & -8.72 & $<0.001$ \\
\hline PCS & 24.65 & 12.70 & 17.66 & 10.43 & -5.54 & $<0.001$ \\
\hline
\end{tabular}

Independent samples t-test; NPRS: Numerical pain rating scale; PCS: Pain catastrophizing scale; SD: Standard deviation; $\mathrm{p}<0.05^{*}$.

Table 3. The predictive power of NPRS and PCS scores for Lasegue positivity

\begin{tabular}{ccccc} 
B Wald Odds & $\mathbf{R}^{2}$ & $\mathbf{p}$ & $\begin{array}{c}95 \% \\
\text { confidence } \\
\text { interval }\end{array}$ \\
\hline Min $\quad$ Max
\end{tabular}

\begin{tabular}{llllllll}
\hline Model & & & & & & & \\
NPRS & 0.56 & 53.68 & 1.75 & 0.24 & $<0.001$ & 1.50 & 2.03 \\
Constant & -3.32 & 47.42 & 0.03 & & & & \\
$\begin{array}{c}\text { Model } \\
\text { PCS }\end{array}$ & 0.05 & 26.74 & 1.05 & 0.11 & $<0.001$ & 1.03 & 1.07 \\
Constant & -0.95 & 16.93 & 0.38 & & & & \\
\hline
\end{tabular}

Simple logistic regression analysis; $\mathrm{R}^{2}$ : Nagelkerke R square; NPRS: Numerical pain rating scale; PCS: Pain catastrophizing scale; $\mathrm{p}<0.05^{*}$.

positivity of Lasegue test was found to be $82 \%$ in 50 cases, whose disc herniation was confirmed by surgical intervention and radiology. In our study, the Lasegue sign was found to be positive in 182 of 345 cases who presented 
with the complaint of low back pain, and in 162 (89\%) of these cases, herniation findings were confirmed by radiology, similar to the rates in the studies mentioned. In addition to these studies, one study reported that only $56.8 \%$ $(n=54 / 95)$ of the patients who underwent microdiscectomy had a positive pre-operative Lasegue sign ${ }^{[17]}$.

It is known that NPRS is used to determine the severity of pain in various diseases, including low back pain ${ }^{[7,8]}$. Various studies have shown that patients with a LP sign have more severe pain and more severe psychological distress than LN patients ${ }^{[18,19]}$. One of the important findings of our study is that the patients in the LP group had higher NPRS scores. Moreover, in the logistic regression analysis, it was revealed that NPRS is one of the factors that can predict Lasegue positivity. It is seen that these findings are in parallel with the literature. Pain perception is influenced by a variety of psychological factors, including destructive thoughts. In the study conducted to evaluate these psychological factors, lower PCS scores were found in patients who underwent pain application before lumbar surgery ${ }^{[20]}$. In the fMRI examination following neuroscience training in a case report, three distinct differences were found, compared to pre-training screening: Deactivation of the periaqueductal gray area, deactivation of the cerebellum, and increased activation of the motor cortex. In this case, it was also reported that a 30 min neuroscience training provided a 10-point decrease in the PCS score ${ }^{[21]}$. Catastrophizing has also been shown to play an important role in modulating post-operative pain in patients undergoing spinal surgery, in whom PCS was used ${ }^{[22]}$. In a comprehensive review, it was reported that pain and disability were associated with catastrophizing in patients with acute, subacute, and chronic low back pain. This review also concluded that catastrophizing as a coping strategy can lead to delayed recovery ${ }^{[23]}$. In a study conducted with a total of 275 participants with the majority (85.5\%) having low back pain for more than 6 weeks, it was found that $52.7 \%$ of the patients were classified as high catastrophizing and they had a significantly higher degree of pain intensity than low catastrophizers $^{[24]}$. In our study, PCS scores of LP patients were found to be higher than LN patients. In addition, PCS was able to predict Lasegue positivity.

\section{Study Limitations}

Disregarding the duration of pain in the study is an important limitation. In addition, the inability to evaluate pain objectively is one of the important limitations of the study.

\section{Conclusion}

The Lasegue sign is one of the most common symptoms in patients with lumbar discopathy. However, it has high sensitivity but low specificity. Different implementation methodologies and interobserver consistency are controversial. Although physical damage is important, various studies have shown that psychological factors are also important in the perception of pain severity. It has also been found that people who are educated about their disease catastrophize pain less. Therefore, it is of great importance that patients are educated and informed both before and after the operation. In addition, it has been reported that pain catastrophizing can affect postural control and should be taken into account in interpreting balance test results when managing chronic low back pain ${ }^{[25]}$. Clinicians should also screen patients with lumbar discopathy for catastrophic and destructive thinking and manage the treatment process with support from other disciplines such as psychiatry when available.

Ethical Committee Approval: Study was approved by the NonInterventional Clinical Research Ethics Committee of Recep Tayyip Erdogan University Faculty of Medicine (17/12/2020 decision number 2020/247).

Peer-review: Externally peer-reviewed.

Authorship Contributions: Concept: O.E.B.; Design: B.Ö.; Supervision: O.E.B.; Fundings: B.Ö.; Materials: O.E.B.; Data Collection or Processing: B.Ö.; Analysis or Interpretation: O.E.B.; Literature Search: B.Ö.; Writing: O.E.B.; Critical Review: B.Ö.

Conflict of Interest: None declared.

Financial Disclosure: The authors declared that this study received no financial support.

\section{References}

1. Bonica-Loeser J. Low back pain. In: Loeser J, editor. Bonica's manag pain. Philadelphia, PA: Lippincott Williams \& Wilkins; 2001. p. 1508-64.

2. Loney PL, Stratford PW. The prevalence of low back pain in adults: A methodological review of the literature. Phys Ther 1999;79:384-96. [CrossRef]

3. Türkiye İstatistik Kurumu (TUIK). Bireylerin Son 12 ay Iç̧erisinde Yaşadığı Başlıca Hastalık/Sağlık Sorunlarının Cinsiyete Göre Dağılımı; 2016.

4. Yıldız EO. Bel ağrısı. In: Beyazova M, Kutsal YG, editors. Fiz Tıp ve Rehabil. Ankara: Güneş Kitabevi; 2000. p. 1465-83.

5. Greenberg MS. Nöroşirürji El Kitabı. $6^{\text {th }}$ ed. İstanbul: Güneş Tıp Kitabevleri; 2013.

6. Ham P, Leiber JD. Physical examination of the lumbar spine. In: Seidenberg PH, Beutler Al, editors. The Sports Medicine Resource Manual. Philadelphia, PA:WB Saunders; 2008. p. 100-9. 
7. Childs JD, Piva SR, Fritz JM. Responsiveness of the numeric pain rating scale in patients with low back pain. Spine (Phila Pa 1976) 2005;30:1331-4. [CrossRef]

8. Michener LA, Snyder AR, Leggin BG. Responsiveness of the numeric pain rating scale in patients with shoulder pain and the effect of surgical status. J Sport Rehabil 2011;20:115-28.

9. Granot M, Ferber SG. The roles of pain catastrophizing and anxiety in the prediction of postoperative pain intensity: A prospective study. Clin J Pain 2005;21:439-45. [CrossRef]

10. Fernandes L, Storheim K, Lochting I, Grotle M. Cross-cultural adaptation and validation of the Norwegian pain catastrophizing scale in patients with low back pain. BMC Musculoskelet Disord 2012;13:111. [CrossRef]

11. Sullivan MJL, Bishop SR, Pivik J. The pain catastrophizing scale: Development and validation. Psychol Assess 1995;7:524-32.

12. Süren M, Okan I, Gökbakan AM, Kaya Z, Erkorkmaz Ü, Arici S, et al. Factors associated with the pain catastrophizing scale and validation in a sample of the Turkish population. Turk J Med Sci 2014;44:104-8. [CrossRef]

13. Yap JC, Lau J, Chen PP, Gin T, Wong T, Chan I, et al. Validation of the Chinese pain catastrophizing scale (HK-PCS) in patients with chronic pain. Pain Med 2008;9:186-95. [CrossRef]

14. Kamath SU, Kamath SS. Lasègue's sign. J Clin Diagn Res 2017;11:RG01-2. [CrossRef]

15. Kosteljanetz M, Bang F, Schmidt-Olsen S. The clinical significance of straight-leg raising (Lasègue's sign) in the diagnosis of prolapsed lumbar disc. Interobserver variation and correlation with surgical finding. Spine (Phila Pa 1976) 1988;13:393-5.

16. Aşkın G, Çobanoglu S, Özsüer H, Şimşek O, Ekuklu G. Lomber disk herniasyonunda siyatik sinir germe testlerinin önemi. Türk Nöroşirürji Derg 2000;10:26-31.

17. Falavigna A, Righesso O, Teles AR, Kleber FD, Canabarro CT, da
Silva PG. Is the lasègue sign a predictor of outcome in lumbar disc herniation surgery? Coluna 2013;12:304-7. [CrossRef]

18. Selim AJ, Ren XS, Fincke G, Deyo RA, Rogers W, Miller D, et al. The importance of radiating leg pain in assessing health outcomes among patients with low back pain. Results from the veterans health study. Spine (Phila Pa 1976) 1998;23:470-4.

19. BenDebba M, Torgerson WS, Long DM. A validated, practical classification procedure for many persistent low back pain patients. Pain 2000;87:89-97. [CrossRef]

20. Louw A, Diener I, Puentedura EJ. The short term effects of preoperative neuroscience education for lumbar radiculopathy: A case series. Int J Spine Surg 2015;9:11. [CrossRef]

21. Louw A, Puentedura EJ, Diener I, Peoples RR. Preoperative therapeutic neuroscience education for lumbar radiculopathy: A single-case $\mathrm{fMRI}$ report. Physiother Theory Pract 2015;31:496-508. [CrossRef]

22. Dunn LK, Durieux ME, Fernández LG, Tsang S, Smith-Straesser $\mathrm{EE}$, Jhaveri HF, et al. Influence of catastrophizing, anxiety, and depression on in-hospital opioid consumption, pain, and quality of recovery after adult spine surgery. J Neurosurg Spine 2018;28:119-26. [CrossRef]

23. Wertli MM, Eugster R, Held U, Steurer J, Kofmehl R, Weiser S. Catastrophizing-a prognostic factor for outcome in patients with low back pain: A systematic review. Spine J 2014;14:263957. [CrossRef]

24. Ogunlana MO, Odole AC, Adejumo A, Odunaiya N. Catastrophising, pain, and disability in patients with nonspecific low back pain. Hong Kong Physiother J 2015;33:73-9. [CrossRef]

25. Zhang C, Zhang Z, Li Y, Feng C, Meng H, Gao Y, et al. Pain catastrophizing is related to static postural control impairment in patients with nonspecific chronic low back pain: A cross-sectional study. Pain Res Manag 2020;2020:9629526. [CrossRef] 